\title{
Pluriannual experience in stapled haemorrhoidopexy in the elderly
}

\author{
S Spirch ${ }^{1}$, F Tona ${ }^{2}$, C Sperti ${ }^{2}$, M Gruppo ${ }^{1}$, F Mazzalai ${ }^{1}$, R Lorenzetti ${ }^{1}$, M Di Giunta ${ }^{1}$, C Sirianni ${ }^{3}$, O Terranova ${ }^{1}$ \\ From XXIII Annual Meeting of the Italian Society of Geriatric Surgery \\ Lecce, Italy. 2-4 December 2010
}

\section{Background}

Compare two groups of patients, $\geq 70$ years old and $<70$ years old, diagnosed with III-IV grade haemorrhoids that underwent to stapled haemorrhoidopexy [1].

\section{Materials and methods}

Between May 2001 and August 2010, 320 patients underwent stapled haemorrhoidopexy (PPH EthiconEndoSurgery $\left.{ }^{\circledR}\right)$. The database has been organised into two groups: the first composed of 30 patients (9.3\%) aged $\geq 70$, while the second composed of 290 patients aged $<70$. The preferred type of anaesthesia was spinal with sedation (92.8\%), combined with elastomeric pump of NSAIDs during the first 24 hours. The two groups were compared in order to verify their homogeneity: no significant differences were found either in the distribution of the grade of the disease, or in the spectrum of symptoms $(\mathrm{P}>>0.05)$. Because of the comorbidity in the elderly, the stratification of the ASA risk was different $(\mathrm{P}<0.0001)$.

\section{Results}

The procedure was performed in day surgery, with an average length of stay of 1 day, in $75 \%$ of the patients of the first group and in the $92 \%$ of the second group; the analysis of the surgical performance of this technique, regarding the timing and the use of haemostatic stitches, showed no significant differences between the two groups $(\mathrm{P}>>0.05)$. Early haemorragic post-operative complications were $2.3 \%$, of which 1 occurred in the first group and 6/7 required surgical review. There were 10 late haemorragic complications, all of them occurred in the second group; the management of the late

\footnotetext{
* Correspondence: tona007@libero.it

${ }^{2}$ Dipartimento di Scienze Mediche e Chirurgiche, Clinica Chirurgica IV, Università di Padova, Italy

Full list of author information is available at the end of the article
}

haemorrhages required surgical review in $40 \%$ of patients and blood transfusion in $30 \%$ of cases. During the first post-operative week several cases of significant anal pain occurred, tenesmus, faecal urgency and two cases of haemorrhoidal thrombosis. During the followup, which lasted on average for 4.1 years, we observed 3 relapses (10\%) among the first group and 21 relapses (7.2\%) among the second.

\section{Conclusions}

Haemorrhoidal disease, although tending to relapse among susceptible patients, can be effectively treated with stapled haemorrhoidopexy (PPH). Thanks to a several years' follow-up, our experience shows an assessment of the long-term results of this technique, focusing particularly on the comparison between the results in the elderly and in younger patients. The Longo technique is usually well tolerated by all the patients, even though not totally pain-free in the early post-operative follow-up (first week). This procedure can be performed safely in the elderly as well as in the younger patients with equivalent results.

\section{Author details \\ ${ }^{1}$ Dipartimento di Scienze Chirurgiche e Gastroenterologiche, Clinica Chirurgica Geriatria, Università di Padova, Italy. ${ }^{2}$ Dipartimento di Scienze Mediche e Chirurgiche, Clinica Chirurgica IV, Università di Padova, Italy. ${ }^{3}$ Senior House Officer, Medicine and A\&E Directorate, Leicester Royal Infirmary, UK.}

Published: 24 August 2011

\section{Reference}

1. Longo A: Cura chirurgica della malattia emorroidaria mediante riduzione del prolasso mucoso ed emorroidario con suturatice. Atti 5th Int Meeting of Coloproctology 1998, 231-9.

doi:10.1186/1471-2318-11-S1-A60

Cite this article as: Spirch et al:: Pluriannual experience in stapled haemorrhoidopexy in the elderly. BMC Geriatrics 2011 11(Suppl 1):A60.
C Biomed Central

() 2011 Spirch et al; licensee BioMed Central Ltd. This is an open access article distributed under the terms of the Creative Commons Attribution License (http://creativecommons.org/licenses/by/2.0), which permits unrestricted use, distribution, and reproduction in any medium, provided the original work is properly cited. 